\title{
Intelligent monitoring system for crowd and social distancing with mask
}

\section{detection.}

\section{Problem / Question}

COVID 19 requires efficient crowd monitoring and social distancing. We have surveillance everywhere but needs vast human resource to monitor in real time.

\section{Variables / Research}

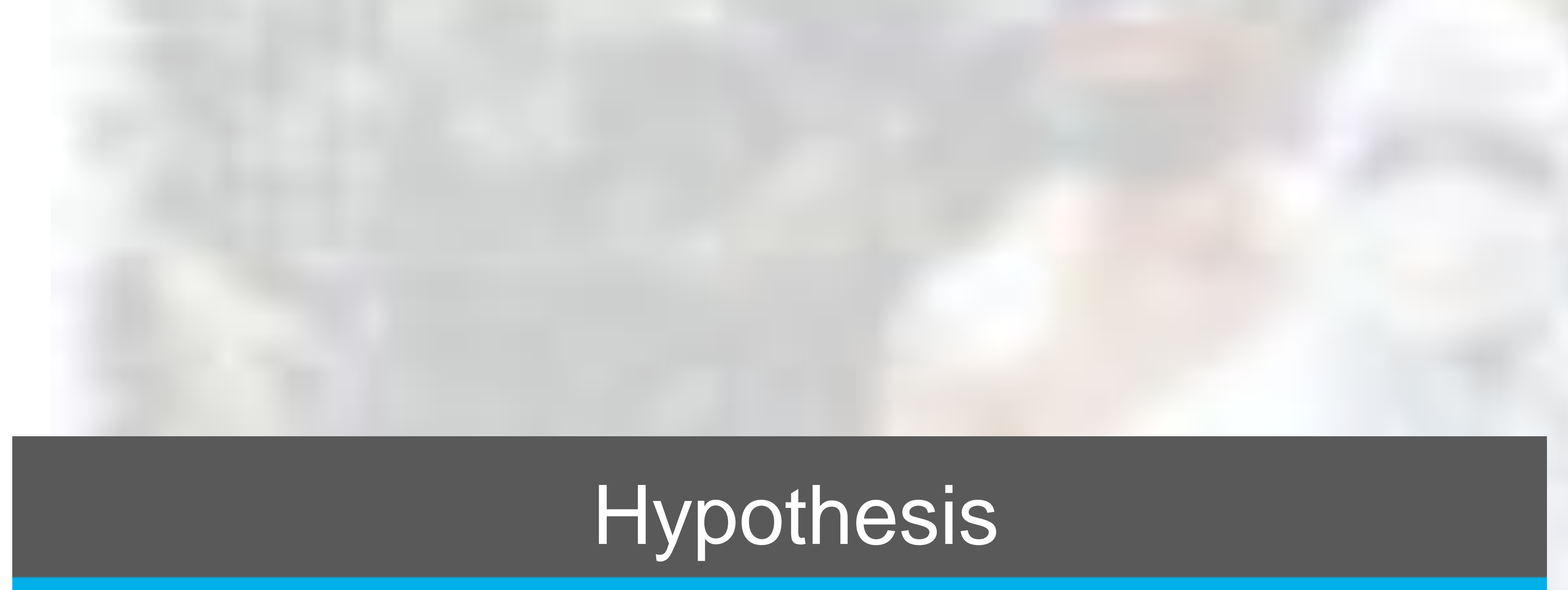

Efficient intelligent monitoring of crowd and social distancing with identifying individuals without masks.

\section{Project Overview}

Use surveillance system to make smart decision by monitoring crowd

Identify non-social distancing people in the crowd

Identify people not wearing masks.

Sending an alert incase of non-compliance to rules of crowd gathering, social distancing and wearing masks.
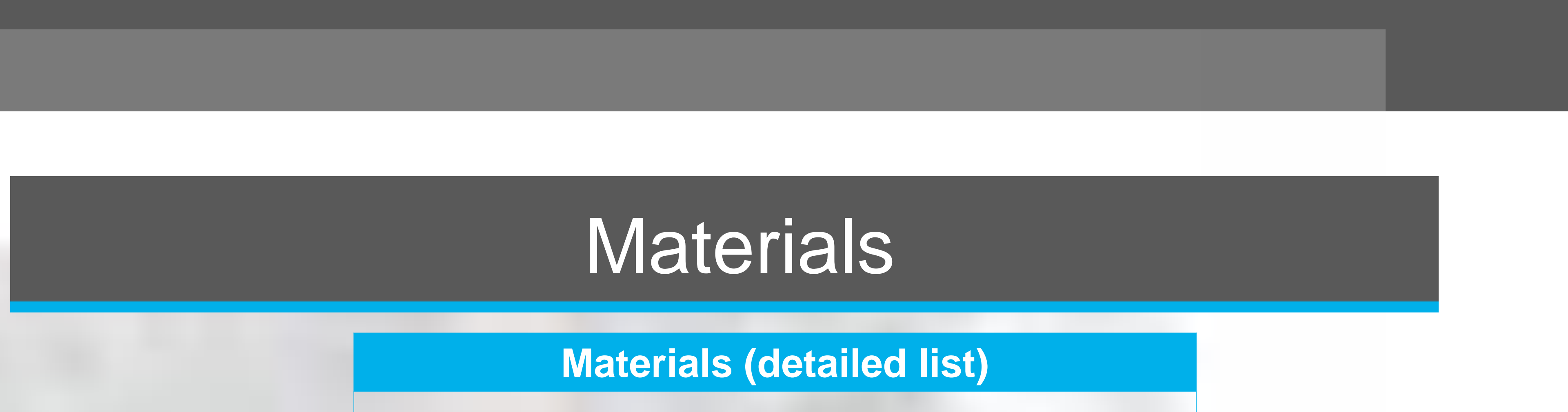

- MOXA3k Data set

- Deep learning equipment

- An alert system
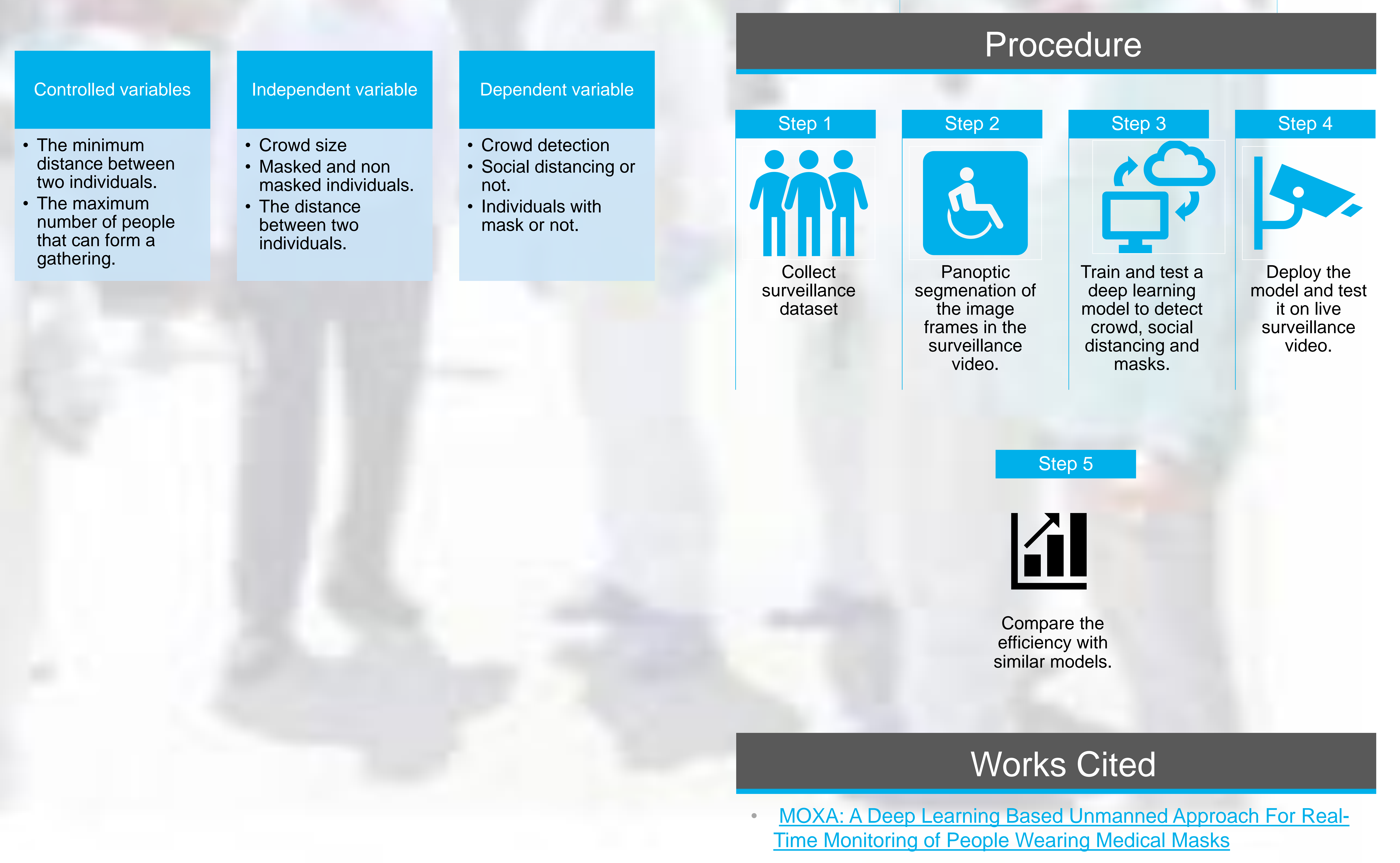